\title{
Composition, habitat preference and seasonal variation of malaria vector larval and pupa stage in Akure North Local Government Area of Ondo State, Nigeria
}

\author{
T. A. Olusi, I. A. Simon-Oke and A. V. Akeju* (1)
}

\begin{abstract}
Background: The study of habitat preference and identification of malaria vector is one of the important steps in malaria control. Knowledge of local Anopheles mosquitoes capable of transmitting malaria parasites has contributed largely to the reduction in the menace caused by malaria infection. This present study examined the habitat nature and identified the species of Anopheles mosquitoes involved in malaria parasites transmission in the study area. Monthly collection and identification of the fourth larval stage was carried out from October 2018 to September 2019.

Result: The prevalence of An. gambiae complex and An. funestus larvae was 95.86 and 4.15\%, respectively. The highest (14.17\%) and the least (4.25\%) number of larvae were collected in the month of November and May, respectively. Out of the total number of Anopheles mosquito larvae collected during the wet season, $69.77 \%$ of the larvae was collected from the clean habitat, while $30.23 \%$ was collected from the dirty habitats. During the dry season, the larvae dwell more in dirty aquatic habitat, with $64.74 \%$ of the larvae collected from the dirty habitats, while $35.27 \%$ was recorded from clean habitats. Statistically, there was no significant difference in the electrical conductivity when comparing both seasons $\left(P=0.19 ; X^{2}=53.14\right)$. The average recorded electrical conductivity in dry and wet seasons were $350.76 \mu \mathrm{S} / \mathrm{cm}$ and $178.91 \mu \mathrm{S} / \mathrm{cm}$, respectively. The $\mathrm{pH}$ recorded in dry and wet seasons were 6.78 and 7.04 , respectively. There was no significant difference in the $\mathrm{pH}$ when both seasons were compared $\left(P=0.13 ; X^{2}=54.89\right)$. The total dissolve solid where not significant different $\left(P=0.58 ; X^{2}=13.35\right)$ when both seasons were compared. The temperature $\left(P=0.04 ; X^{2}=43.54\right)$ and dissolve oxygen $\left(P=0.00 ; X^{2}=30.09\right)$ were significantly different comparing dry and wet seasons in all the habitats where the immature stages of Anopheles mosquitoes were collected.
\end{abstract}

Conclusion: The study revealed major vector of malaria parasite in the study location, also the pattern of their breeding during dry and rainy season which is influenced by some selected ecological factors.

Keywords: Anopheles gambiae, Anopheles funestus, Habitat, Dry and rainy seasons

\section{Background}

Anopheles mosquito is the most studied and well-known genus of mosquito, largely because of their great impact on human health. As vector of etiologic agent of malaria and filariasis, Anopheles mosquitoes have affected the

\footnotetext{
*Correspondence: akejuav@futa.edu.ng; adebayoakeju@gmail.com
}

Federal University of Technology Akure, Akure, Ondo State, Nigeria lives of more humans than any other insect. Human malaria is caused by either one or more of the protozoan parasites: Plasmodium falciparum, P. malariae, P. vivax and $P$. ovale (Antinori et al. 2012). Among these, P. falciparum causes the deadliest form of human malaria and the most prevalent in tropical parts of the world. The genus Anopheles contain over four hundred recognized species of Anopheles and about 50 members of Anopheles species involved in transmitting human malaria 
parasites (Tabue et al. 2017). The most important species of malaria vector in Africa, where incident of malaria disease is highest, are Anopheles gambiae, An. funestus, An. arabiensis and An. colluzzi (Wiebe et al. 2017).

Proper understanding of malaria vector oviposition behavior and habitat characterization study will help in combating and reducing the burden of malarial disease (Muema et al. 2017). The habitats of Anopheles are specifically different compared to other genus of mosquitoes. The immature stages of Anopheles mosquito occur in many different types of large and more or less permanent habitats, ranging from freshwater, mangrove swamps, rice fields, edges of streams, drainage pits, rivers and ponds (Walshe et al. 2017). They are also found in small and often temporary breeding places such as puddles, hoof prints, well, discarded tins and sometimes waterstorage pots. Each species has different biological behavior, which made them distinct from each other (Nandi et al. 2000). The larvae of Anopheles mosquitoes are more abundant in temporary habitat characterized with direct sunlit and low emergent vegetation (Getachew et al. 2020). These habitats may have negative influence in supporting the life of other organisms that may serve as predators or compete with the immature stages of the mosquito (Roux and Robert 2019). The depth knowledge of oviposition sites and distribution pattern of Anopheles larvae and pupae will help in managing the vector. Control of the larvae and pupae of malaria vectors can be advantageous because the immature stages are relatively immobile and occupy a specific habitat, compared to the adults that are active and readily mobile. The information on larval habitats, species composition and distribution is among the easiest way in strategic planning of malaria control (Tabbabi et al. 2015). Thus, the implementation of control plan against immature stages (larvae and pupae) of the malaria vector will reduce adult emergence and indirectly suppress the transmission of malaria parasites. Therefore, this study evaluated the composition, habitat preference and seasonal variation in physiochemical factors of Anopheles mosquito larvae habitat in Akure North Local Government of Ondo State, Nigeria.

\section{Methods}

\section{Study area}

Akure North Local Government has an area of $660 \mathrm{~km}^{2}$ and a population of 131,587 (National Population Commission 2009). The five locations where Anopheles mosquito samples were collected are Oba-Ile, Igoba, Isinigbo, Ita-Ogbolu and Iju (Fig. 1). These locations were selected for the study due to the increasing in the population and expansion of the area, which as result involved numerous activities which support the breeding of mosquitoes. The breeding sites were identified by random sampling of stagnant water in drainages, pond, river edges and open soil surfaces. The geographical positioning coordinate of the collection sites was taken using geographical positioning system mobile device.

\section{Collection of anopheles mosquito larvae and pupae}

Larvae and Pupae were randomly collected between 8 and $11 \mathrm{am}$ in the morning from different breeding sites identified in the study area during dry season (October 2018 to February 2019) and wet season (March 2019 to September 2019). The breeding sites were characterized according to their nature (dirty and clean). Anopheles larvae were identified by their characteristic horizontal positioning on the surface of the water. The larvae and pupae were carefully collected into plastic containers of $750 \mathrm{ml}$ from each of the identified breeding habitats by scooping gently to avoid injury; this was carried out thrice a month. The same process of collection was considered for both dry and wet seasons to avoid bias. Each sample was labeled indicating date, site and locality of collection. The containers were loosely capped to avoid suffocation and immediately transported to Biology laboratory at Federal University of Technology Akure.

\section{Morphological identification of mosquitoes}

The larvae were identified under dissecting microscope using standard morphological characters keys supplied by Das et al. (1990) and Nagpal and Sharma (1995). Species identification was done based on taxonomic keys published by Gillies and Coetzee (1987).

\section{Determination of physicochemical parameters of Anopheles mosquitoes immature stage habitats}

Physicochemical parameters such as $\mathrm{pH}$, temperature, electrical conductivity, dissolve oxygen, temperature and total dissolve solid were determined in situ during sampling three times per month for a period of twelve months. Electrical conductivity (range 0-9999 $\mu \mathrm{S} / \mathrm{cm}$ ) and temperature (range $0-80{ }^{\circ} \mathrm{C}$ ) were determined using Aqua-pro water tester (model-AP2). The $\mathrm{pH}$ was determined using Aquarium pool IA digital meter (model-PH 009; range $0.0-14.0 \mathrm{pH}$ ). Amtast dissolved oxygen meter (model-AMT08; range 0.0-19.9 mg/L) was used to determine dissolve oxygen. The total dissolved solids of the habitat were determined using Hanna instrument total dissolved meter (model-DIST 1; range 10-1990 ppm).

\section{Data analysis}

The variation in seasonal and habitat nature was statistically analyzed using statistical package for social science version 22 software. Chi-square test was use to determined difference between season variation that exist between the physicochemical parameter both in dry and 


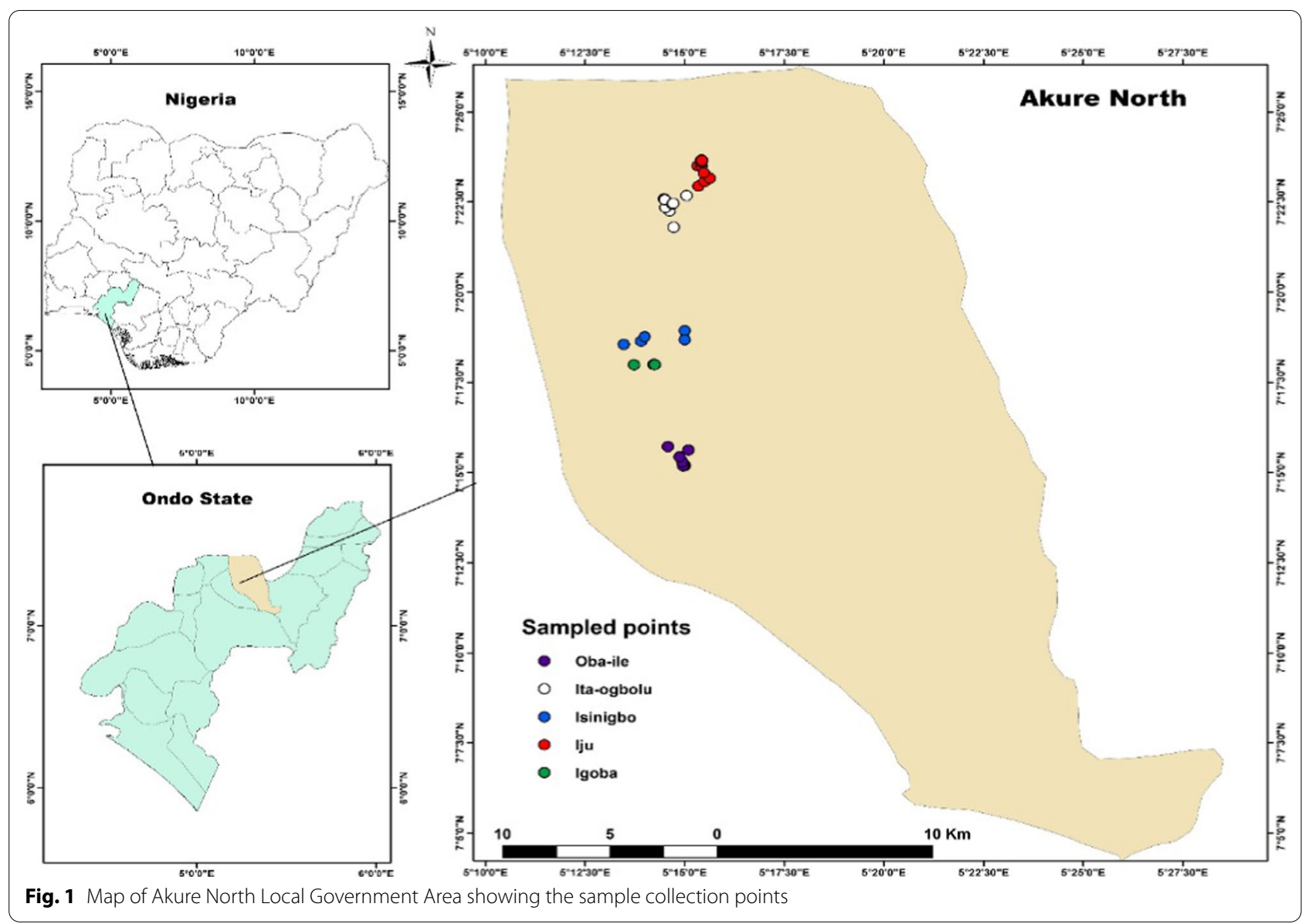

wet season. Frequency distribution graph was use to compare the abundant of the vectors in both seasons and nature of the habitats.

\section{Results}

\section{Monthly collection of Anopheles mosquito larvae in the study areas}

The total monthly collection of Anopheles mosquito larvae is shown in Table 1. The highest percentage of Anopheles larvae was collected in the month of November (14.17\%) followed by $13.71 \%$ in December, while the least was recorded in the month of May (4.25\%). The larvae and pupae of An. gambiae complex constituted $95.86 \%$ and $95.99 \%$ of all the collected samples, while $4.15 \%$ and $4.00 \%$ were recorded for An. funestus. Figure 2 shows the distribution of malaria vector larvae and the nature of the breeding sites. The percentage of Anopheles larvae collected from dirty habitats were high in month of November (68.51\%) during the dry season. The habitat shifted during the raining season, while the highest percentage of Anopheles mosquito larvae was collected from clean habitant in the month of May (87.69\%).
The overall seasonal distribution and composition of Anopheles larvae are presented in Fig. 3. During the dry season, Anopheles mosquito larvae have more preference for dirty habitats than clean habitats. A higher percentage of $64.74 \%$ of Anopheles mosquito larvae were collected from dirty habitat, while $35.27 \%$ were recorded from clean habitat. In rainy season, a higher percentage of Anopheles mosquito larvae occupy clean habitat compared to dirty habitat with $69.77 \%$ and $30.23 \%$ larvae recorded for clean and dry habitats, respectively. Table 2 showed the habitats characterized in the study area. Pond bed, River bed and Rivers edges are potential breeding sites for Anopheles mosquito larvae and pupae during dry season while pot-hole, Tyre racks, abandon containers and Rain pool accommodate immature stages of Anopheles mosquitoes during the rainy season.

Table 3 shows that the Electrical conductivity of the habitats is higher during the dry season $(350.76 \pm 60.07)$ than the rainy season $(178.91 \pm 48.65)$ with no significant difference between the two seasons $(P=0.19)$. The $\mathrm{pH}$ of the habitats was neutral during the rainy season (7.04 \pm 0.33 ), while that of the dry season was slightly acidic $(6.78 \pm 0.20)$. There was a slight change 
Table 1 Monthly collection of Anopheles mosquito larvae and pupae from habitats in the Study Areas (750 ml of water per collection)

\begin{tabular}{|c|c|c|c|c|c|c|c|c|c|}
\hline \multirow[t]{3}{*}{ Months } & \multicolumn{3}{|c|}{ An. gambiae complex } & \multicolumn{3}{|c|}{ An. funestus group } & \multicolumn{3}{|l|}{ Total } \\
\hline & Larvae & Pupa & Total & Larvae & Pupae & Total & Larvae & Pupa & Total \\
\hline & (\%) & (\%) & $(\%)$ & $(\%)$ & $(\%)$ & $(\%)$ & (\%) & $(\%)$ & $(\%)$ \\
\hline October & $742(12.19)$ & $81(6.49)$ & $823(11.23)$ & $34(12.93)$ & $12(23.08)$ & $46(14.60)$ & $776(12.23)$ & $93(7.16)$ & $869(11.13)$ \\
\hline November & $858(14.12)$ & $96(7.69)$ & $954(13.02)$ & $41(15.59)$ & $18(34.62)$ & $59(18.73)$ & $899(14.17)$ & $114(8.78)$ & 1013(13.25) \\
\hline December & $824(13.55)$ & $112(8.98)$ & $936(12.77)$ & $46(17.49)$ & - & $46(14.60)$ & $870(13.71)$ & $112(8.62)$ & $982(12.85)$ \\
\hline January & $591(9.72)$ & $124(9.94)$ & $715(9.76)$ & $68(25.89)$ & $05(9.62)$ & $73(23.18)$ & 659 (10.39) & $129(9.93)$ & $788(10.31)$ \\
\hline February & $433(7.12)$ & $162(12.99)$ & $595(8.12)$ & $54(20.52)$ & $12(23.08)$ & $66(20.95)$ & $487(7.68)$ & $174(13.39)$ & $661(8.65)$ \\
\hline March & $482(7.93)$ & $154(12.35)$ & $636(8.68)$ & $10(3.81)$ & $05(9.62)$ & $15(4.76)$ & $492(7.75)$ & $159(12.24)$ & $651(8.52)$ \\
\hline April & $578(9.50)$ & $116(9.30)$ & $694(9.47)$ & - & - & - & $578(9.11)$ & $116(8.93)$ & $694(9.08)$ \\
\hline May & $249(4.09)$ & 76 (6.09) & $325(4.43)$ & - & - & - & $249(3.92)$ & $76(5.85)$ & $325(4.25)$ \\
\hline June & $344(5.66)$ & 101 (8.09) & $445(6.07)$ & - & - & - & $344(5.42)$ & $101(7.78)$ & $445(5.82)$ \\
\hline July & $321(5.28)$ & $28(2.25)$ & $349(4.76)$ & - & - & - & $321(5.06)$ & $28(2.16)$ & $349(4.57)$ \\
\hline August & $297(4.88)$ & $108(8.66)$ & $405(5.53)$ & - & - & - & $297(4.68)$ & $108(8.31)$ & $405(5.29)$ \\
\hline September & $363(5.97)$ & 89 (7.14) & $452(6.17)$ & $10(3.81)$ & - & $10(3.18)$ & $373(5.88)$ & 89 (6.85) & $462(6.04)$ \\
\hline Total & $6082(95.86)$ & $1247(95.99)$ & 7329 (95.88) & $263(4.15)$ & $52(4.00)$ & $315(4.12)$ & 6345 & 1299 & 7644 \\
\hline
\end{tabular}

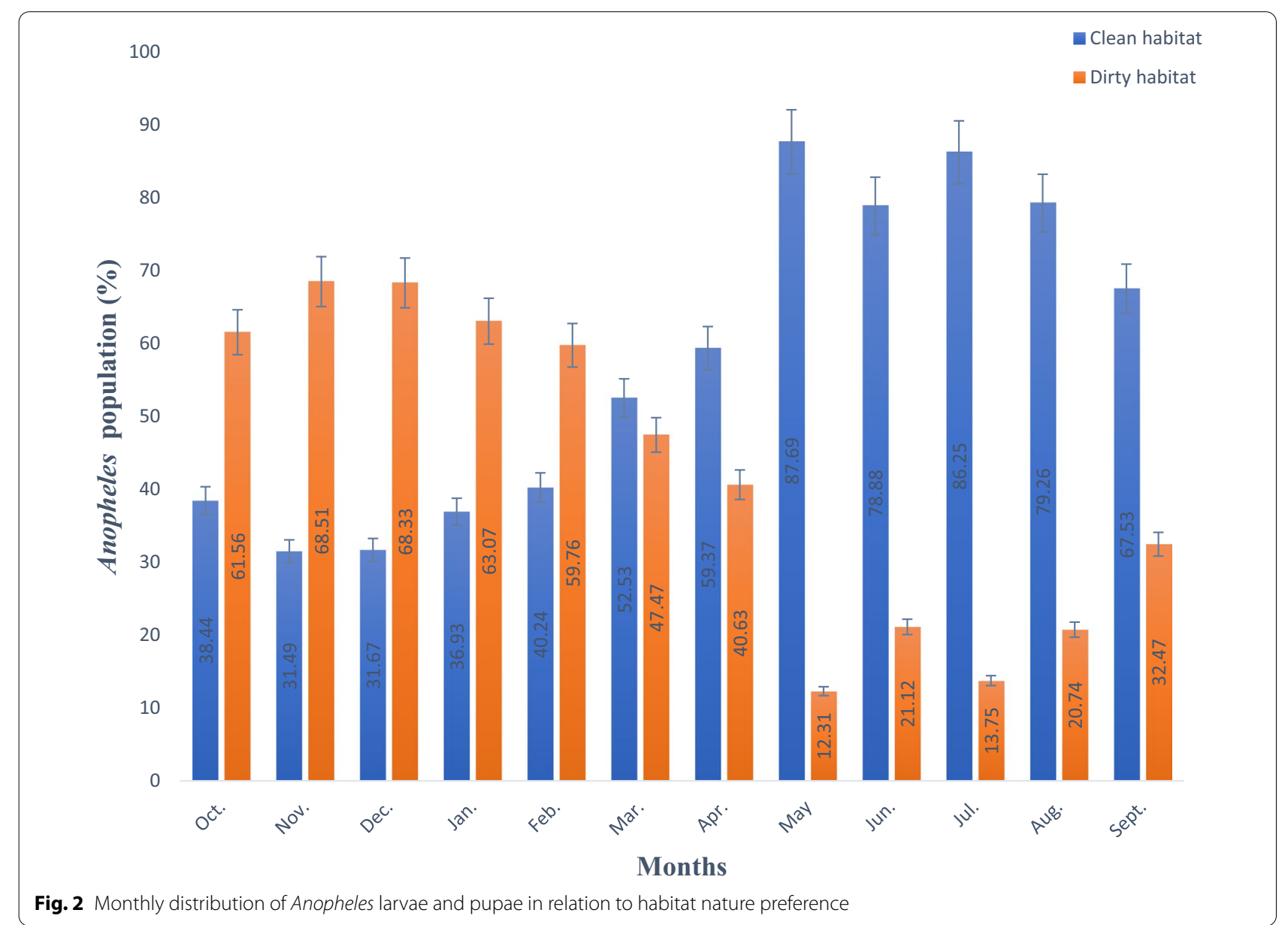




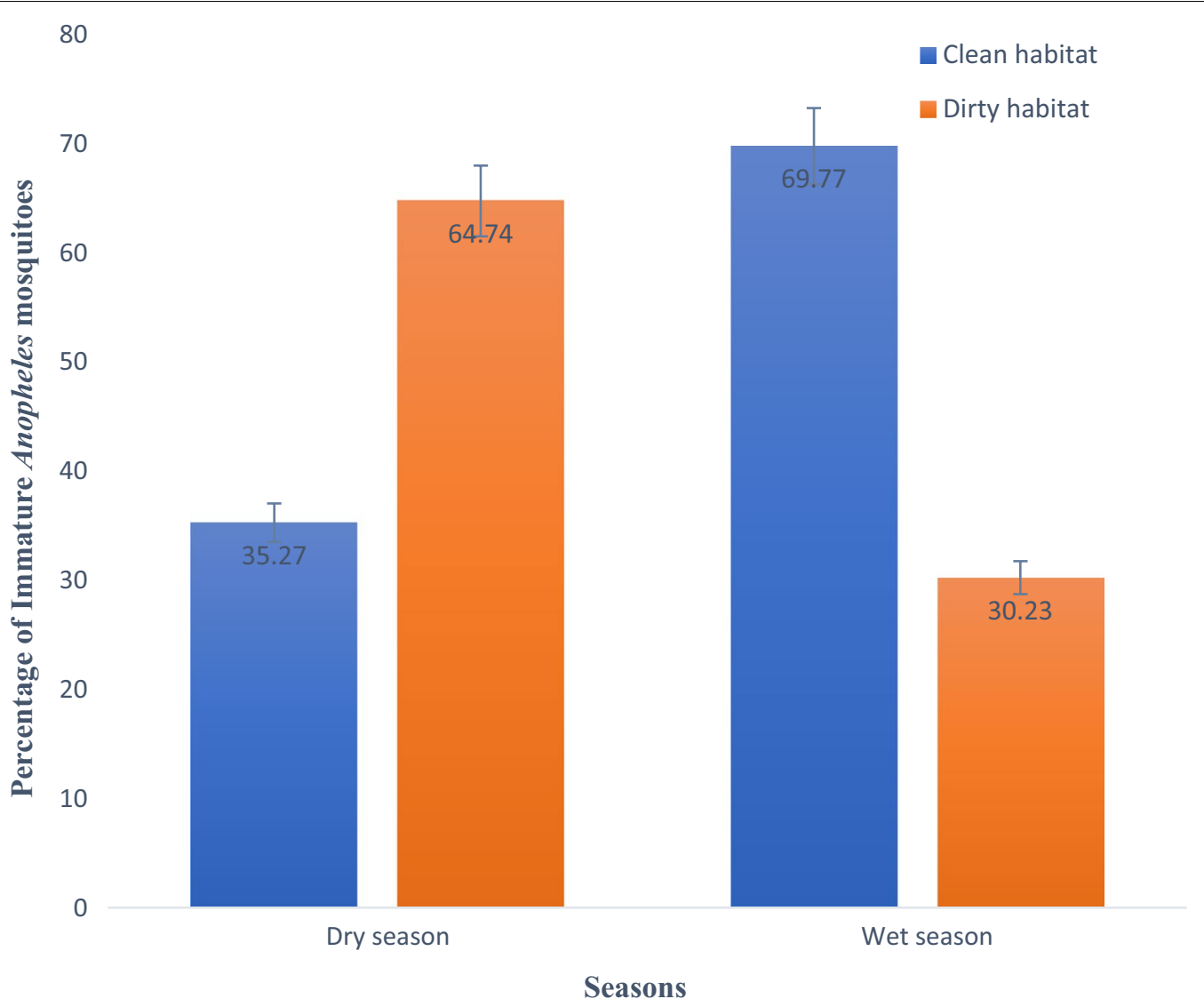

Fig. 3 Seasonal distribution and composition of immature Anopheles mosquitoes in the study areas

Table 2 Habitat preference and seasonal variations of Anopheles mosquitoes larvae and pupae in the study area $(750 \mathrm{ml}$ of water per collection)

\begin{tabular}{|c|c|c|c|c|}
\hline \multirow[t]{2}{*}{ Habitat } & \multicolumn{2}{|c|}{$\begin{array}{l}\text { Anopheles gambiae } \\
\text { complex }\end{array}$} & \multicolumn{2}{|c|}{$\begin{array}{l}\text { Anopheles } \\
\text { funestus group }\end{array}$} \\
\hline & Dry & Wet & Dry & Wet \\
\hline Pond bed & ++ & - & + & - \\
\hline River bed & ++ & - & + & - \\
\hline Spoor & ++ & ++ & + & + \\
\hline Concrete gutter & + & ++ & - & - \\
\hline River edges & ++ & - & + & + \\
\hline Canal & ++ & + & + & - \\
\hline Abandon tyre & - & + & - & - \\
\hline Pot - hole & - & ++ & - & - \\
\hline Gutter & + & ++ & + & - \\
\hline Tyre tracks & - & + & - & - \\
\hline Abandon containers & - & + & - & - \\
\hline Rain pool & - & ++ & - & - \\
\hline
\end{tabular}

Plus sign (+): present, minus sign (-): absent, double plus sign: multiples of hundreds, single plus sign: multiple of tens in temperature and dissolved oxygen in the mean value recorded from Anopheles mosquito larvae and pupae habitat in both seasons. The temperature recorded for dry and rainy seasons was $27.13^{\circ} \mathrm{C}$ and $25.25^{\circ} \mathrm{C}$, respectively. There was significant different in temperature comparing the seasons $(P=0.04)$. The dissolved oxygen from both seasons was significantly different $(P=0.00)$.

\section{Discussion}

The immature stages of An. gambiae complex and An. funestus group encountered in this study showed high preference for clean habitats during the rainy season and dirty habitats during the dry season. There was a shift in habitat preference during the dry season where most of the Anopheles larvae collected were found in dirty or muddy habitats, the highest number of Anopheles immature stages were collected in month of November in dry season. This may be due to disappearance of suitable habitats for oviposition during this period. Charlwood et al. (2000) and Tantely et al. (2016) reported that Anopheles mosquito larvae breed in different habitat during the dry season compare to the rainy season, most especially 
Table 3 Seasonal variation of the physicochemical parameters (mean \pm S.D) of Anopheles larvae habitats

\begin{tabular}{|c|c|c|c|c|c|}
\hline \multirow[t]{2}{*}{ Parameter } & \multicolumn{2}{|l|}{ Season } & \multirow[t]{2}{*}{ Total mean \pm S.D } & \multirow[t]{2}{*}{$x^{2}$} & \multirow[t]{2}{*}{ P-value } \\
\hline & Dry & Wet & & & \\
\hline Electrical conductivity & $350.76 \pm 60.07$ & $178.91 \pm 48.65$ & $250.52 \pm 104.19$ & 53.14 & 0.19 \\
\hline $\mathrm{pH}$ & $6.78 \pm 0.20$ & $7.04 \pm 0.33$ & $6.93 \pm 0.30$ & 54.89 & 0.13 \\
\hline Total dissolved solid & $17.48 \pm 4.23$ & $15.97 \pm 4.05$ & $16.60 \pm 4.01$ & 13.25 & 0.58 \\
\hline Temperature & $27.13 \pm 0.77$ & $25.25 \pm 0.81$ & $26.03 \pm 1.22$ & 43.54 & 0.04 \\
\hline Dissolved oxygen & $7.91 \pm 0.11$ & $8.21 \pm 0.12$ & $8.09 \pm 0.19$ & 30.09 & 0.00 \\
\hline
\end{tabular}

vector of malaria parasites (An. gambiae s. s., An. arabiensis and An. funestus) in Afro-tropical region. Mattah et al. (2017) compared the seasonal variation of the distribution of Anopheles mosquito larvae; it was reported that rainy season has a significant high proportion of the Anopheles mosquito immature stages compared to dry season. The present study showed that the immature stages of Anopheles mosquitoes increased during dry season, though there was no significantly different when comparing the proportion of the immature stages of Anopheles mosquitoes in both seasons. Minakawa et al. (2001) and Magombedze et al. (2018) reported that $A n$. gambiae Giles and An. arabiensis survive in large number during the dry season in a way that remain unknown.

The appearance of An. funestus during dry season shows that the vector contributed to the malaria infection rate during this season. The appearance could be as a result of reduction in potential breeding sites for oviposition since most of the habitats are dried up. Charlwood et al. (2000) and Getachew et al. (2020) suggested that since the habitat suitable for Anopheles species breeding dried up during the dry season, the malaria vector could migrate several kilometers in searching for suitable breeding sites, it was also suggested that the vector that transmits malaria during this season is immigrants from several kilometers away during this period. The outcome of this study was supported the report of Ondiba et al. (2019) where it was reported that the suitable period for most mosquito species to thrived was during the dry season, though it was reported that there was no significant different in survival rate of mosquito larvae between the two seasons (rainy and dry season). The result of this research also supported the findings of Zogo et al. (2019), who reported that the percentage of Anopheles mosquito larvae was higher during the dry season compare wet season. However, it is contrast to the report of Mattah et al. (2017), who reported high proportion of Anopheline mosquito larvae during the raining season compared to the dry season.

The positive habitats for Anopheles mosquitoes in the study area include Pond bed, River bed, Animal spoors, Concrete gutter, River edges, Canal, abandon tires, Pot-holes, Gutter, Tyre tracks, abandon containers and Rain pool, and this was correlated with what was reported by Elmalih et al. (2018) in Sudan. Other mosquitoes larval and organisms found in the habitat are Aedes larval, Culex larval, Culiseta larval, Tadpoles and Dragon fly larval, while some habitats were characterized with vegetation. Among the habitats, pond bed, river bed, spoors/foot tracks, gutter and canal are positive for Anopheles mosquitoes during dry season and all these habitats are within human dwelling, Dida et al. (2018) and Getachew et al. (2020) reported some of these habitats for Anopheles mosquitoes larvae. During rainy season, rain pool, abandon containers, spoors, gutter and abandon tyres are home of the immature stages of this vector in the study area.

The electrical conductivity of the Anopheles immature stages habitat is high in dry season than in rainy season. Ajani et al. (2018) reported that water bodies containing the immature stages of Anopheles mosquitoes are higher in electrical conductivity during dry season than in rainy season. Anopheles mosquitoes larval has been reported to thrived more in habitat with high electrical conductivity (Othaman et al. 2020). The total dissolved solid recorded from the habitats in dry season was a little bit high more than what was recorded in rainy season. The total dissolved solid recorded in this study was extremely low compared to what was reported from other findings (Emidi et al. 2017). In rainy season, the $\mathrm{pH}$ of the habitats was a bit higher than neutral compare to the $\mathrm{pH}$ in dry season which is slightly lower and below neutral. The $\mathrm{pH}$ recorded in all the habitats where immature Anopheles mosquitoes were collected are in conformity with the report of Tirado et al. (2017). There was a significant different in temperature of the Anopheles mosquito (larvae and pupae) habitats in both seasons, the temperature of the habitat is slightly higher in dry season than in rainy season. The temperature recorded in both seasons supported the development of immature stages of Anopheles mosquitoes, and this was in agreement with the report of ChristiansenJucht et al. (2014) and Ajani et al. (2018). 


\section{Conclusion}

This study has exposed the breeding pattern of malaria parasites vectors in the study location. All Anopheles mosquitoes identified in the study area are epidemiologically important for malaria transmission. The immature stages of Anopheles mosquito mostly prefer clean aquatic environment during the raining seasons, though, immature stages have high population during the dry season and positively associated with dirty habitats.

\section{Acknowledgements}

The authors appreciate the Chief Laboratory Technologist of the Department of Biology, Federal University of Technology, Akure for her support. We also appreciate the support of Isaac Olabimi and Kolade Orimolade for their assistance during sample collection.

\section{Authors' contributions}

OTA, SIA and AAV contributed to the research design and involved in field and laboratory work. AAV carried out statistical analysis and interpret the result of the study. AAV write the first draft of the manuscript. OTA and SIA review the manuscript. All author read and approved the final manuscript.

\section{Funding}

This research work did not receive external funding.

Available of data and materials

All analyzed data involved in this study are included in this manuscript.

\section{Declarations}

Ethics approval and consent to participate

Not applicable.

\section{Consent for publication}

Not applicable.

\section{Competing for interests}

The authors declare that they have no competing interests.

Received: 9 February 2021 Accepted: 4 April 2021

Published online: 10 May 2021

\section{References}

Ajani FO, Ofoezie El, Adeoye N, Eze HI (2018) Anopheles mosquito larval production and association of water bodies with malaria transmission in Ife and Ilesa Areas of Osun State, Nigeria. J Environ Sci Toxicol Food Technol 12(6):82-88

Antinori S, Galimberti L, Milazzo L, Corbellino M (2012) Biology of human malaria plasmodia including Plasmodium Knowlesi. Mediterr J Hematol Infect Dis 4(1):e2012013

Charlwood JD, Vij R, Billingsley PF (2000) Dry season refugia of malaria-transmitting mosquitoes in a dry savannah zone of East Africa. Am J Trop Med Hyg 62(6):726-732

Christiansen-Jucht C, Parham PE, Saddler A, Koella JC, Basáñez M (2014) Temperature during larval development and adult maintenance influences the survival of Anopheles gambiae ss. Parasites Vectors 7:489

Das BP, Rajagopal R, Akiyama J (1990) Pictorial key to mosquitoes species of Indian anopheline mosquitoes. J Pure Appl Zool 2(3):131-162

Dida GO, Anyona DN, Abuom PO, Akoko D, Adoka SO, Matano AS (2018) Spatial distrribution and habitat characterization of mosquito species during the dry season along the Mara River and its tributaries, in Kenya and Tanzania. Infect Dis Poverty 7:2
Elmalih EBI, Almugadam BS, Tamomh AG, Hassan SM (2018) Influence of environmental factors on breeding habitats of mosquito species in Kosti City, White Nile State. Sudan Health Sci J 12(4):577

Emidi B, Kisinza WN, Mmbando BP, Malima R, Mosha FW (2017) Effect of physicochemical parameters on Anopheles and Culex mosquito larvae abundance in different breeding sites in a rural setting of Muheza, Tanzania. Parasites Vectors 10:304

Getachew D, Balkew M, Tekie H (2020) Anopheles larval species composition and characterization of breeding habitats in two localities in the Ghibe River Basin, southwestern Ethiopia. Malar J 19:65

Gillies MT, Coetzee M (1987) A Supplement to the Anophelinae of Africa, South of the Sahara. Publication of the South African institute of International Medicine and Research. No. 55.

Magombedze G, Ferguson NM, Ghani AC (2018) A trade-off between dry season survival longevity and wet season high net reproduction can explain the persistence of Anopheles mosquitoes. Parasites Vectors 11:576

Mattah PAD, Futagbi G, Amekudzi LK, Mattah MM, de Souza DK, Kartey-Attipoe WD, Bimi L, Wilson MD (2017) Diversity in breeding sites and distribution of Anopheles mosquitoes in selected urban areas of southern Ghana. Parasites Vectors 10:25

Minakawa N, Githure Jl, Beier J, Yan G (2001) Anopheline mosquito survival strategies during the dry period in Western Kenya. J Med Entomol 38(3):388-392

Muema JM, Bargul JL, Njeru SN, Onyango JO, Imbahale SS (2017) Prospects for malaria control through manipulation of mosquito larval habitats and olfactory-mediated behavioural responses using plant-derived compounds. Parasites Vectors 10:184

Nagpal BN, Sharma VP (1995) Mosquito taxonomic inventory. Science Publishers Inc., p 416

Nandi J, Kaul SM, Sharma SN, Shiv I (2000) Anthropopily of Anopheles in Daurs of West Bengal and another Region of India. J Common Dis 32:95-99

National Population Commission (NPC) (2009) 2006 Population and Housing Census of the Federal Republic of Nigeria: National and State Population and Housing Tables, Priority Tables (Volume I) National Population Commission. Abuja, Nigeria

Ondiba IM, Oyieke FA, Athinya DK, Nyamongo IK, Estambale BBA (2019) Larval species diversity, seasonal occurrence and larval habitat preference of mosquitoes transmitting Rift Valley fever and malaria in Baringo County, Kenya. Parasites Vectors 12:295

Othaman NNC, Isa MNM, Ismail RC, Ahmad MI, Hui CK (2020) Factors that affect soil electrical conductivity (EC) based system for smart farming application. AIP Conf Proc 2203:020055

Roux O, Robert V (2019) Larval predation in malaria vectors and its potential implication in malaria transmission: an overlooked ecosystem service? Parasites Vectors 12:217

Tabbabi A, Bousses P, Rhim A, Brengues C, Daaboub J, Ben-Alaya-Bouafif N, Fontenille D, Bouratbine A, Simard F, Aoun K (2015) Larval habitats characterization and species composition of Anopheles mosquitoes in Tunisia, with particular attention to Anopheles maculipennis complex. Am J Trop Med Hyg 92:653-659

Tabue RN, Awono-Ambene P, Etang J, Atangana J, Antonio-Nkondjio C, Toto JC, Patchoke S, Leke RGF, Fondjo E, Mnzava AP, Knox TB, Tougordi A, Donnelly MJ, Bigoga JD (2017) Role of Anopheles (Cellia) rufipes (Gough, 1910) and other local anophelines in human malaria transmission in the northern savannah of Cameroon: a cross-sectional survey. Parasites Vectors 10:22

Tantely ML, Le Goff G, Sebastien Boyer S, Fontenille D (2016) An updated checklist of mosquito species (Diptera: Culicidae) from Madagascar. Parasite 23:20

Tirado DF, Almanza-Vasquez E, Almanza-Meza EJ, Acevedo-Correa D, GonzálezMorelo KJ (2017) Larval development of mosquitoes and pH of different reservoirs in the City of Cartagena de Indias (Colombia). Int J Eng Technol 9(6):4137-4140

Walshe DP, Garner P, Adeel AA, Pyke GH, Burkot TR (2017) Larvivorous fish for preventing malaria transmission. Cochrane Database Syst Rev 12:CD008090

Wiebe A, Longbottom J, Gleave K, Shearer FM, Sinka ME, Massey NC, Cameron E, Bhatt S, Gething PW, Hemingway J, Smith DL, Coleman M, Moyes CL (2017) Geographical distributions of African malaria vector sibling species and evidence for insecticide resistance. Malar J 16:85 
Zogo B, Koffi AA, Ahoua Alou LP, Fournet F, Dahounto A, Dabiré RK, Baba Moussa L, Moiroux N, Pennetier C (2019) Identification and characterization of Anopheles spp. breeding habitats in the Korhogo area in northern Côte d'Ivoire: a study prior to a Bti-based larviciding intervention. Parasites Vectors 12:146

\section{Publisher's Note}

Springer Nature remains neutral with regard to jurisdictional claims in published maps and institutional affiliations.
Submit your manuscript to a SpringerOpen ${ }^{\odot}$ journal and benefit from:

- Convenient online submission

- Rigorous peer review

- Open access: articles freely available online

- High visibility within the field

- Retaining the copyright to your article

Submit your next manuscript at $\boldsymbol{\nabla}$ springeropen.com 